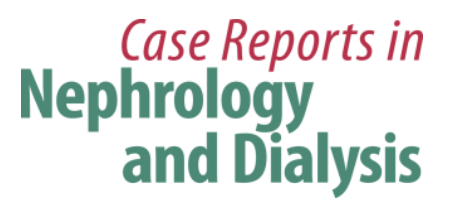

Case Rep Nephrol Dial 2018;8:45-55

DOI: $10.1159 / 000487919$

Publisned online: Vvarch 20, 2018

(c) 2018 The Author(s)

Published by S. Karger AG, Basel

www.karger.com/cnd

This article is licensed under the Creative Commons Attribution-NonCommercial 4.0 International License (CC BY-NC) (http://www.karger.com/Services/OpenAccessLicense). Usage and distribution for commercial purposes requires written permission.

\title{
Membranous Nephropathy-Like Apolipoprotein E Deposition Disease with Apolipoprotein E Toyonaka (Ser197Cys) and a Homozygous Apolipoprotein E2/2
}

\author{
Megumu Fukunaga ${ }^{a}$ Kiyotaka Nagahama $^{\mathrm{b}}$ Michiko Aoki $^{\mathrm{c}}$ \\ Akira Shimizu $^{c}$ Shigeo Hara ${ }^{d}$ Akira Matsunaga ${ }^{e}$ Eri Muso $^{f}$ \\ Takao Saito ${ }^{g}$ \\ ${ }^{a}$ Toyonaka Keijinkai Clinic, Toyonaka, Japan; ${ }^{b}$ Department of Pathology, Kyorin University \\ School of Medicine, Tokyo, Japan; ${ }^{C}$ Department of Analytic Human Pathology, Graduate \\ School of Medicine, Nippon Medical School, Tokyo, Japan; ${ }^{d}$ Department of Diagnostic \\ Pathology, Kobe University Graduate School of Medicine, Kobe, Japan; ${ }^{e}$ Department of \\ Laboratory Medicine, Fukuoka University Hospital, Fukuoka, Japan; ' Division of \\ Nephrology and Dialysis, Kitano Hospital, Tazuke Kofukai Medical Institute, Osaka, Japan; \\ ${ }^{9}$ Sanko Clinic, Fukuoka, Japan
}

\section{Keywords}

Apolipoprotein E Toyonaka · Homozygous apolipoprotein E2/2 - Apolipoprotein E deposition · Membranous nephropathy $\cdot$ Lipoprotein glomerulopathy

\begin{abstract}
A 20-year-old female student underwent renal biopsy because of chance proteinuria and hematuria. Histological study revealed a membranous nephropathy-like appearance by light microscopy. But immunoglobulins and complements were negative in the glomerulus by immunofluorescence study. On the other hand, plasma apolipoprotein E (ApoE) concentra- 


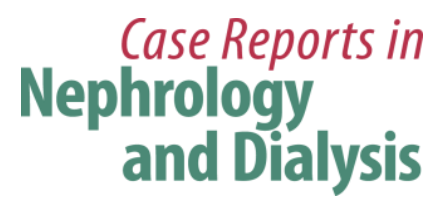

Case Rep Nephrol Dial 2018;8:45-55

DOI: $10.1159 / 000487919$

(C) 2018 The Author(s). Published by S. Karger AG, Basel www.karger.com/cnd

Fukunaga et al:: Membranous Nephropathy-Like Apolipoprotein E Deposition Disease with Apolipoprotein E Toyonaka (Ser197Cys) and a Homozygous Apolipoprotein E2/2

tion was elevated to more than 2 times the normal range, and the phenotype, genotype, and DNA sequence studies of her ApoE showed homozygous ApoE2/2 and a heterozygous novel missense mutation called ApoE Toyonaka (Ser197Cys). Detailed immunohistochemical studies found that the dense deposits in subepithelial, subendothelial, and mesangial areas contained ApoE. Tandem mass spectrometry also proved a large amount of ApoE in the glomerulus. These findings suggest that ApoE Toyonaka with a homozygous ApoE2/2 may cause a new form of ApoE-related glomerular disease resembling membranous nephropathy.

(C) 2018 The Author(s)

Published by S. Karger AG, Basel

\section{Introduction}

Apolipoprotein E (ApoE) is an important component of lipoprotein and plays a major role in the uptake of lipoproteins into cells through low-density lipoprotein receptors [1]. Recently, ApoE abnormalities have gained attention as they are involved in some specific glomerular diseases. Lipoprotein glomerulopathy (LPG) was initially reported in Japan [2] and later known to be associated with various heterozygous ApoE variants, e.g., ApoE Sendai [3] and ApoE Kyoto [4]. This disease is histologically characterized by lipoprotein thrombi without foam cells in the glomerular capillary [5] and clinically improved by fibrates, although its prognosis is sometimes poor and recurrence has been observed in transplanted kidneys [5]. On the other hand, ApoE2 homozygous glomerulopathy showing marked foam cell infiltration has been reported [6].

Here, we present a case with a novel ApoE mutant, which we named ApoE Toyonaka, and a homozygous ApoE2/2. The histological findings by light microscopy (LM) looked like membranous nephropathy (MN), but no immunoglobulin was identified with immunofluorescence (IF) staining. Highly dense and microbubbling deposits were observed by electron microscopy (EM), and a large amount of ApoE was recognized by immunohistochemistry and tandem mass spectrometry (MS/MS). These findings suggest that an ApoE Toyonaka associated with a homozygous ApoE2/2 may induce a new form of ApoE-related glomerular disease, which is different from LPG and ApoE2 homozygous glomerulopathy.

\section{Case Presentation}

A 20-year-old Japanese female student was admitted to Toyonaka Municipal Hospital in 2006 in order to undergo examinations, including renal biopsy, because she was found to have chance proteinuria and hematuria at the health surveillance in her university. On admission, she was $171 \mathrm{~cm}$ tall and weighed $68.1 \mathrm{~kg}$. Her blood pressure was 124/90 mm Hg and her pulse rate was $75 /$ min with no arrhythmia. No abnormal finding was identified by physical examination. Her laboratory findings are described in Table 1. Significant proteinuria and hematuria with hypoalbuminemia were recognized, but the criteria for nephrotic syndrome were not satisfied. Other values, including lipids and renal functions, were within normal ranges. 


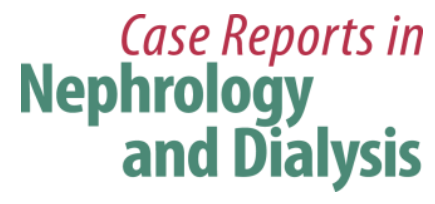

Case Rep Nephrol Dial 2018;8:45-55

DOI: $10.1159 / 000487919$

C 2018 The Author(s). Published by S. Karger AG, Basel www.karger.com/cnd

Fukunaga et al.: Membranous Nephropathy-Like Apolipoprotein E Deposition Disease with Apolipoprotein E Toyonaka (Ser197Cys) and a Homozygous Apolipoprotein E2/2

\section{Pathological Findings}

On renal biopsy, more than 30 glomeruli were contained in LM specimens, some of which showed global sclerotic change. Neither mesangial cell proliferation nor mesangial matrix expansion was marked (Fig. 1a). In silver methenamine-stained sections, "spike" formation as seen in MN was found in most of the glomeruli (Fig. 1b). Foam cells were not found in any glomeruli, but in the interstitial area. On IF staining, very weak linear patterns were identified for IgG and C3 in glomeruli, but a granular pattern as seen in MN was not identified (data not shown). EM study showed highly dense deposits in the subepithelial, subendothelial, and mesangial areas, which appeared like microbubbles or microcysts on higher magnification (Fig. 1c, d).

\section{Clinical Course after the First Biopsy}

Based on the renal histological findings, in spite of the almost negative results on IF study, MN was diagnosed, and treatment with prednisolone and cyclosporine A was started. The combination of 2 immunosuppressive agents initially seemed effective because of decreased urinary protein. When the dosages were gradually lowered, however, urinary protein was persistent between 0.5 and $2.5 \mathrm{~g} / \mathrm{gCr}$. The estimated glomerular filtration rate was slowly reduced but became stable at around $50 \mathrm{~mL} / \mathrm{min} / 1.73 \mathrm{~m}^{2}$ after 5 years of the first biopsy. Mild anemia was observed initially, and the hemoglobin level further decreased corresponding with the decline in estimated glomerular filtration rate. After the administration of an erythropoiesis-stimulating agent, however, it was more than $10 \mathrm{~g} / \mathrm{dL}$.

\section{Analysis of ApoE Mutation}

Although serum triglycerides and cholesterol were within normal limits (Table 1), the plasma ApoE concentration was high (LCAT: $82 \mathrm{nmol} / \mathrm{mL}$; ApoA1: $187 \mathrm{mg} / \mathrm{dL}$; ApoA2: 32.1 mg/dL; ApoB: $52 \mathrm{mg} / \mathrm{dL}$; ApoE: $10.4 \mathrm{mg} / \mathrm{dL}$ ). Since this finding suggested an ApoE abnormality, the ApoE phenotype, genotype, and ApoE DNA sequence of the patient were examined.

Plasma ApoE phenotypes were analyzed by isoelectric focusing polyacrylamide gel electrophoresis and immunoblotting analysis, as previously reported $[3,4]$. The patient's sample showed the position of ApoE2/2 (Fig. 2a, lane 1).

The ApoE genotype was determined by restriction fragment length polymorphism analysis, as described previously [3,4]. The polymerase chain reaction (PCR) products were digested with the restriction enzyme Hhal. Genotype $\varepsilon 2 / 2$ in the patient was identified by 91- and 83-bp fragments (Fig. 2b, lane 1). The ApoE Toyonaka (Ser197Cys), as shown in Figure 2d, was also confirmed by restriction fragment length polymorphism analysis digested with SacI (Fig. 2c). Genomic DNA was amplified by PCR using oligonucleotide primers,

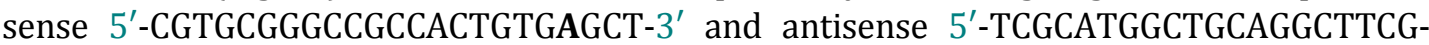
GCGTTC-3'. The 335-bp fragment after cleavage by SacI suggested normal c.644C of ApoE in codon 197 (Fig. 2c, lane 3). The 358- and 335-bp fragments after cleavage by SacI showed a heterozygous novel mutation of ApoE Toyonaka (Fig. 2c, lane 2).

Sequencing of ApoE DNA was performed as described previously [7]. As a result, in our patient, we identified a homozygous polymorphism at codon $158(\varepsilon 2 / 2$ : c.526 C>T: Arg158Cys) (data not shown) and a heterozygous missense mutation (C to G) in exon 4 lead- 


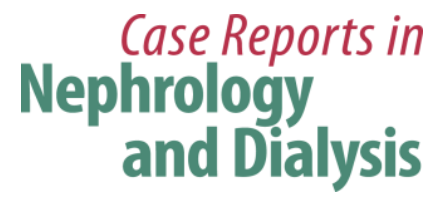

Case Rep Nephrol Dial 2018;8:45-55

DOI: $10.1159 / 000487919$

(C) 2018 The Author(s). Published by S. Karger AG, Basel www.karger.com/cnd

Fukunaga et al.: Membranous Nephropathy-Like Apolipoprotein E Deposition Disease with Apolipoprotein E Toyonaka (Ser197Cys) and a Homozygous Apolipoprotein E2/2

ing to an amino acid substitution Cys (TGC) for Ser (TCC) at codon 197 (c.644 C>G: p.S215C: Ser197Cys) (Fig. 2d).

\section{The Second Renal Biopsy}

The first biopsy showed MN-like findings, but immune deposits were not proven there, and immune-genetic MN was doubtful. Meanwhile, the gene examination for ApoE revealed the coexistence of ApoE Toyonaka and ApoE2/2, suggesting the involvement of a new form of ApoE-related disease. To clarify the accurate pathological changes, a second renal biopsy was conducted 9 years after the first one. Although the histological findings by LM and IF were similar to those of the first biopsy, the density of deposits on EM were more obvious, and ApoE was identified by immunohistochemical studies for LM and EM specimens using anti-ApoE antibody (Novus Biologicals, Littleton, CO, USA) (Fig. 3) [8].

\section{Tandem Mass Spectrometry}

In order to determine the glomerular deposits, an analysis by means of liquid chromatography-assisted MS/MS (LC-MS/MS) of glomeruli obtained from both renal biopsies using laser capture microdissection method was performed as previously reported [9]. In brief, glomeruli in a 10- $\mu \mathrm{m}$-thick section of formalin-fixed paraffin-embedded tissue stained with hematoxylin were microdissected with laser microdissection (PALM MicroBeam, Carl Zeiss, Oberkochen, Germany). Ten glomeruli were analyzed for each specimen. Microdissected fragments were digested into peptides using trypsin and analyzed on amazon ETD (Bruker Daltonics, Billerica, MA, USA) using LC-MS/MS. Peptides present in raw data files were queried by the use of Mascot and X!Tandem, the results were then assigned peptide and protein probability scores, and they were displayed by the use of Scaffold software (Proteome Software Inc., Portland, OR, USA). As a result, the most abundant protein was ApoE in both samples (Fig. 4).

\section{Discussion}

The initial renal biopsy in the current case showed thickening of the glomerular tufts with various degree of "spike" formation, which is usually observed in MN. Therefore, immunosuppressive therapy usually applied to MN was performed, but its effect was not sufficient. On the other hand, because plasma ApoE concentration was more than 2 times the normal range, phenotype, genotype, and DNA sequence of ApoE were analyzed. As a result, ApoE Toyonaka (Ser197Cys), a novel mutant, was detected together with classical homozygous ApoE2/2. Now, 2 diseases should be considered when such mutations are recognized; one is LPG [5] and the other is ApoE2 homozygous glomerulopathy [6]. Clinically, severe proteinuria is recognized in both, but hematuria is usually negative, different from the current case $[5,6]$. Although several mutations in the APOE gene have been reported in LPG cases, the histological characteristics are almost common to all of these cases [5]. LM examination of the renal biopsy specimen shows marked dilatation of the capillary lumina with pale-stained substances in the glomerulus, which are observed on EM to consist of fingerprint-like substances with fine granules called lipoprotein thrombi [2]. On the other hand, foam cell infiltration is marked in ApoE2 homozygous glomerulopathy [6]. In contrast, in the 


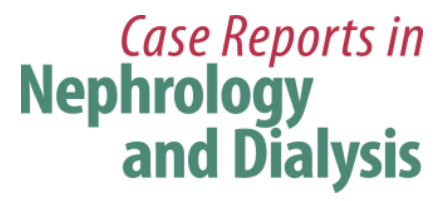

Case Rep Nephrol Dial 2018;8:45-55

DOI: $10.1159 / 000487919$

(C) 2018 The Author(s). Published by S. Karger AG, Basel www.karger.com/cnd

Fukunaga et al.: Membranous Nephropathy-Like Apolipoprotein E Deposition Disease with Apolipoprotein E Toyonaka (Ser197Cys) and a Homozygous Apolipoprotein E2/2

current case, various degrees of "spike" formation, which is usually observed in $\mathrm{MN}$, were seen in most of the glomeruli, with neither lipoprotein thrombi nor foam cells in them. In IF specimens, however, no specific staining for immunoglobulins was observed, different from that of MN due to immune mechanisms in which fine granular deposits of IgG and C3 along the glomerular basement membrane are identified. Meanwhile, ApoE deposits were identified in subepithelial, subendothelial, and mesangial areas in the glomerulus by the immunohistochemical studies for LM (Fig. 3a) and in EM specimens (Fig. 3b, c). Moreover, MS/MS proved that ApoE was abundantly included in the glomerulus. Although the histological findings are far different from those of LPG and of ApoE2 homozygous glomerulopathy, these findings suggest that the current case belongs to one of the ApoE-related renal diseases. Actually, it has been reported in LPG that osmiophilic substances accumulate in the subendothelial and mesangial areas [10-12], and occasionally microbubbles appear [10].

This case has extremely unique findings in relation to LPG and MN. Compared to LPG, the representative ApoE-related glomerulopathy, the characteristic lipoprotein thrombi were not observed in the glomerulus. On the other hand, spike formations and electron dense deposits characteristic of MN were found in the subepithelial area and less frequently in the subendothelial and mesangial areas. Interestingly, different from MN, these deposits did not include either immunoglobulins nor complements but ApoE. In previous studies on LPG, osmiophilic granular substances were reported in the subendothelial and mesangial areas [10-12], and one of them showed ApoE deposition and microbubbles like in the current case [10]. But there was no report that showed subepithelial deposits forming spikes.

The secondary MN-like lupus nephritis sometimes has the subendothelial and mesangial deposits as well as the subepithelial ones. But the association with collagen diseases was not observed in this case. Accordingly, it may be possible that these electron dense deposits are not composed of immune complexes but lipoproteins with abnormal ApoE mainly.

In the current case, the coexistence of a novel mutant called ApoE Toyonaka and a classical homozygous ApoE2 was observed, but it can be considered that ApoE Toyonaka is responsible for these renal lesions, because the pathology of ApoE2 homozygous glomerulopathy with type III hyperlipoproteinemia and glomerular foam cells is much different from that of the current case. Actually, ApoE Toyonaka occurs in the hinge region (amino acid residues 192-215) that stabilizes the connection between the N-terminal domain having low-density lipoprotein receptor-binding region and the C-terminal domain having lipids-binding activity [13]. Therefore, such a missense mutation in the hinge region may induce dysfunction of the $\mathrm{C}$-terminal domain and result in the normolipidemic peculiar glomerular lesions without foam cells or lipoprotein thrombi. In addition, several LPG cases have been discovered due to high serum ApoE even without hyperlipidemia [14, 15]. When ApoE-related kidney disease is suspected, serum ApoE should be examined for a differential diagnosis.

In $\mathrm{MN}$, it is suggested that the subepithelial deposits are accumulated by the in site formation of endogenous antigens and circulating IgG antibodies, and the M-type phospholipase A2 receptor (PLA2R) has recently gained attention as a major antigen in human idiopathic MN [16]. But it is not possible that ApoE is involved in $\mathrm{MN}$ as an endogenous antigen.

Meanwhile, in LPG, there is a possibility that ApoE variants substituted by proline or cysteine induce severe structural changes and cause lipoprotein thrombi via charge abnormality or alternative receptor binding activity $[4,17,18]$. Moreover, since the molecular size of ApoE (34 kD) is much smaller than that of albumin (68 kD), ApoE can cross the anionic 
charge barrier in the glomerular basement membrane and accumulate in the subepithelial area. However, this is the first case in which ApoE was identified in the subepithelial area, and further studies adding similar cases are needed.

In conclusion, MN-like lesions mainly having subepithelial deposition were recognized in a patient with a novel ApoE mutation called ApoE Toyonaka and a classical homozygous ApoE2/2 variant. Since IgG and complements were not identified in the glomerulus, but ApoE was there, it was suggested that this case showed a new form of ApoE-related glomerular disease.

\section{Acknowledgements}

We thank Drs. Dedong Kang and Hidenori Suzuki (Nippon Medical School, Tokyo, Japan) for their excellent technical assistance and Dr. Masanobu Takeji (Toyonaka Municipal Hospital, Osaka, Japan) for the assistance on the second renal biopsy. This work was supported in part by a Grant-in-Aid for Scientific Research (C) from Japan Society for the Promotion of Science (16K08698, K.N.).

\section{Statement of Ethics}

The authors have no ethical conflicts to disclose.

\section{Disclosure Statement}

The authors have no conflicts of interest to disclose.

\section{References}

1 Dominiczak MH, Caslake MJ: Apolipoproteins: metabolic role and clinical biochemistry applications. Ann Clin Biochem 2011;48:498-515.

Saito T, Sato H, Kudo K, Oikawa S, Shibata T, Hara Y, Yoshinaga K Sakaguchi H: Lipoprotein glomerulopathy: glomerular lipoprotein thrombi in a patient with hyperlipoproteinemia. Am J Kidney Dis 1989;13:148-153.

-3 Oikawa S, Matsunaga A, Saito T, Sato H, Seki T, Hoshi K, Hayasaka K, Kotake H, Midorikawa H, Sekikawa A, Hara S, Abe K, Toyota T, Jingami H, Nakamura H, Sasaki J: Apolipoprotein E Sendai (arginine $145 \rightarrow$ proline): a new variant associated with lipoprotein glomerulopathy. J Am Soc Nephrol 1997;8:820-823.

4 Matsunaga A, Sasaki J, Komatsu T, Tsuji E, Moriyama K, Koga T, Arakawa K, Oikawa S, Saito T, Kita T, Doi T: A novel apolipoprotein E mutation, E2 (Arg25Cys), in lipoprotein glomerulopathy. Kidney Int 1999;56:421-427.

5 Saito T, Matsunaga A, Oikawa S: Impact of lipoprotein glomerulopathy on the relationship between lipids and renal diseases. Am J Kidney Dis 2006;47:199-211.

6 Kawanishi K, Sawada A, Ochi A, Moriyama T, Mitobe M, Mochizuki T, Honda K, Oda H, Nishikawa T, Nitta K: Glomerulopathy with homozygous apolipoprotein E2: a report of three cases and review of the literature. Case Rep Nephrol Urol 2013;3:128-135. 


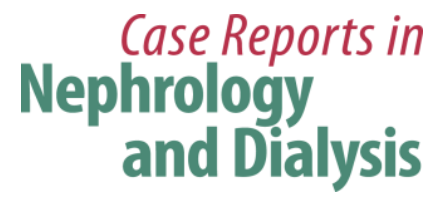

Case Rep Nephrol Dial 2018;8:45-55

DOI: $10.1159 / 000487919$

(C) 2018 The Author(s). Published by S. Karger AG, Basel www.karger.com/cnd

Fukunaga et al.: Membranous Nephropathy-Like Apolipoprotein E Deposition Disease with Apolipoprotein E Toyonaka (Ser197Cys) and a Homozygous Apolipoprotein E2/2

Kinomura M, Sugiyama H, Saito T, Matsunaga A, Sada K, Kanzaki M, Takazawa, Maeshima Y, Yanai H, Makino H: A novel variant apolipoprotein E Okayama in a patient with lipoprotein glomerulopathy. Nephrol Dial Transplant 2008;23:751-756.

Oliver C: Postembedding labeling methods. Methods Mol Biol 2010;588:387-395.

$>9$

Vrana JA, Gamez JD, Madden BJ, Theis JD, Bergen III HR, Dogan A: Classification of amyloidosis by laser microdissection and mass spectrometry-based proteomic analysis in clinical biopsy specimens. Blood 2009;114:4957-4959.

10 Zhang P, Matalon R, Kaplan L, Kumar A, Gallo G: Lipoprotein glomerulopathy: first report in a Chinese male. Am J Kidney Dis 1994;24:942-950.

11 Saito T, Oikawa S, Sato H, Chiba J: Lipoprotein glomerulopathy and its pathogenesis. Contrib Nephrol 1997;120:30-38.

12 Saito T, Oikawa S, Sato H, Ito S, Sasaki J: Lipoprotein glomerulopathy: significance of lipoprotein and ultrastructural features. Kidney Int 1999;71:S32-S41.

13 Tudorache IF, Trusca VG, Gafencu AV: Apolipoprotein E - a multifunctional protein with implications in various pathologies as a result of its structural features. Comput Struct Biotechnol J 2017;15:359-365.

-14 Saito T, Sato H, Oikawa S, Kudo S, Kurihara I, Nakayama K, Abe K, Yoshinaga K, Sakaguchi H: Lipoprotein glomerulopathy: report of a normolipidemic case and review of the literature. Am J Nephrol 1993;13:64-68.

15 Konishi K, Saruta T, Kuramochi S, Oikawa S, Saito T, Matsunaga A, Sasaki J: Association of a novel 3amino acid deletion mutation of apolipoprotein E (Apo E Tokyo) with lipoprotein glomerulopathy. Nephron 1999;83:214-218.

16 Beck LH Jr, Bonegio RG, Lambeau G, Beck DM, Powell DW, Cummins TD, Klein JB, Salant DJ: M-type phospholipase A2 receptor as target antigen in idiopathic membranous nephropathy. N Engl J Med 2009;361:11-21.

-17 Hoffmann M, Scharnagl H, Panagiotou E, Banghard W, Wieland H, März W: Diminished LDL receptor and high heparin binding of apolipoprotein E2 Sendai associated with lipoprotein glomerulopathy. J Am Soc Nephrol 2001;12:524-530.

18 Georgiadou D, Stamatakis K, Efthimiadou EK, Kordas G, Gantz D, Chroni A, Stratikos E: Thermodynamic and structural destabilization of ApoE3 by hereditary mutations associated with the development of lipoprotein glomerulopathy. J Lipid Res 2013;54:164-176. 


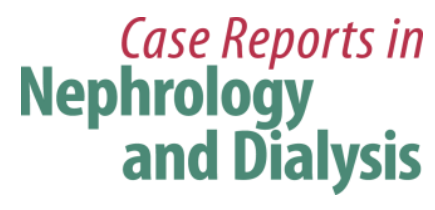

Case Rep Nephrol Dial 2018:8:45-55
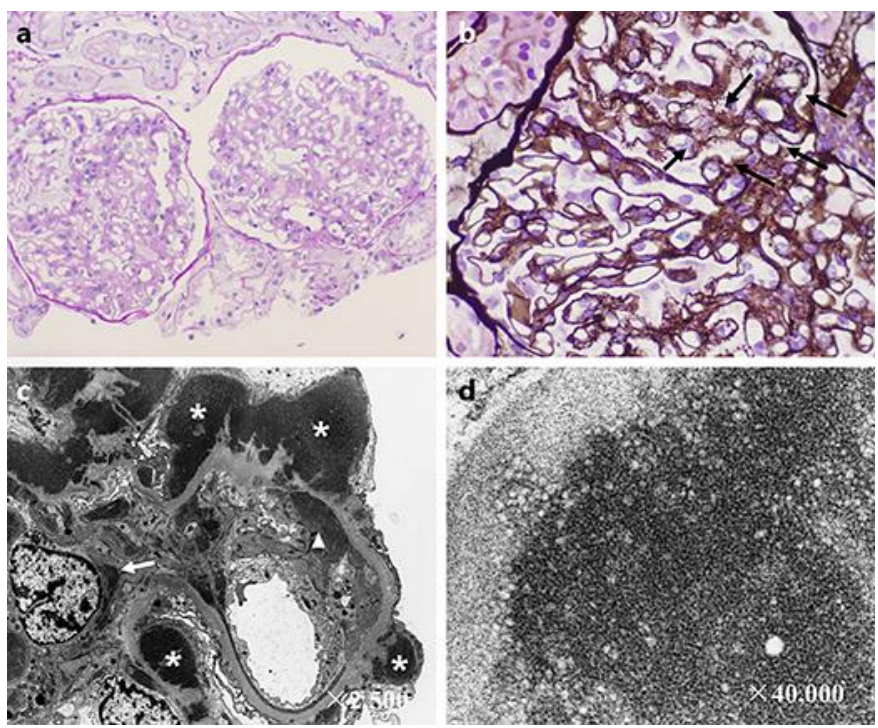

Fig. 1. Light microscopic and electron microscopic findings in the glomerulus on the first renal biopsy. a PAS staining: neither mesangial proliferation nor mesangial matrix expansion is identified. b Silver methenamine staining: spike formation is found in most of the glomeruli (arrows). c Electron microscopic findings $(\times 2,500)$ : highly electron dense deposits are found in subepithelial (asterisks), subendothelial (arrowhead), and mesangial areas (arrow). d Electron microscopic findings $(\times 40,000)$ : on larger magnification, highly electron dense deposits consist of microbubbles or microcysts. 


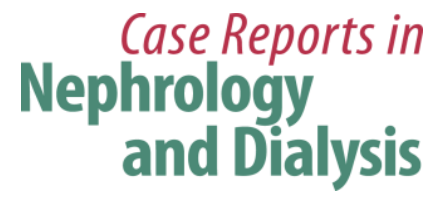

\begin{tabular}{l|l} 
Case Rep Nephrol Dial 2018:8:45-55 \\
\begin{tabular}{l|l} 
DOI: $10.1159 / 000487919$ & $\begin{array}{l}\text { C } 2018 \text { The Author(s). Published by S. Karger AG, Basel } \\
\text { www.karger.com/cnd }\end{array}$
\end{tabular}
\end{tabular}

Fukunaga et al.: Membranous Nephropathy-Like Apolipoprotein E Deposition Disease with Apolipoprotein E Toyonaka (Ser197Cys) and a Homozygous Apolipoprotein E2/2

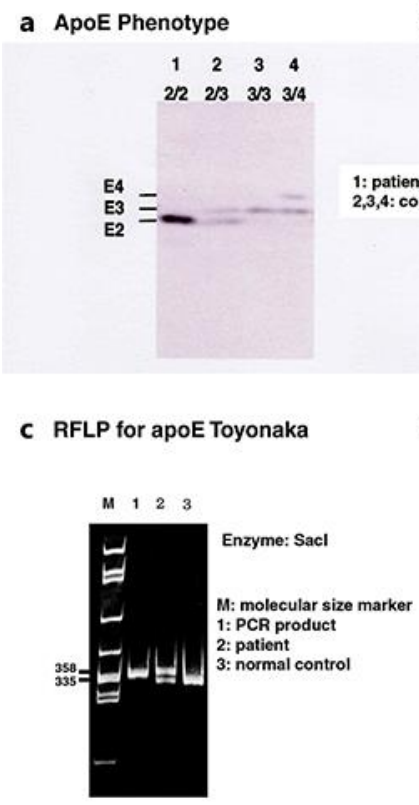

b ApoE Genotype

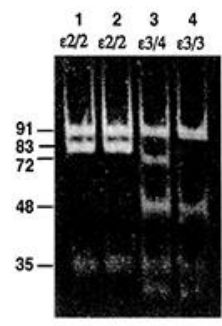

Enzyme: Hha I

1: patient

2,3,4: control

patient

d DNA sequence

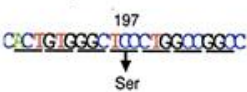

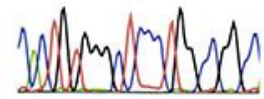

Normal

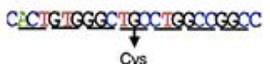

cys

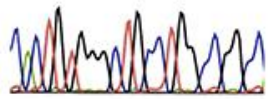

Mutation

Fig. 2. Phenotype, genotype, and DNA sequence of ApoE in the patient. a ApoE phenotype analysis. The patient was identified as E2/2 (lane 1). Controls (lanes 2, 3, and 4) show E2/3, E3/3, and E3/4, respectively. b ApoE genotype analysis by RFLP using HhaI as a restriction enzyme. The patient was identified as $\varepsilon 2 / 2$. Controls (lanes 2,3 , and 4) show $\varepsilon 2 / 2, \varepsilon 3 / 4$, and $\varepsilon 3 / 3$, respectively. c RFLP for ApoE Toyonaka using Sacl as a restriction enzyme. Lanes M, 1, 2, and 3 show marker, PCR only, the patient (ApoE Toyonaka), and normal control, respectively. $\mathbf{d}$ Sequence analysis of $A P O E$ gene. A heterozygous missense mutation (c.644 $\mathrm{C}>\mathrm{G}$ ) in exon 4 leads to an amino acid substitution Cys (TGC, lower) for Ser (TCC, upper) at codon 197. ApoE, apolipoprotein E; RFLP, restriction fragment length polymorphism. 


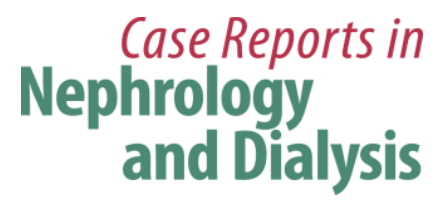

Case Rep Nephrol Dial 2018;8:45-55

DOI: $10.1159 / 000487919$

(C) 2018 The Author(s). Published by S. Karger AG, Basel www.karger.com/cnd

Fukunaga et al.: Membranous Nephropathy-Like Apolipoprotein E Deposition Disease with Apolipoprotein E Toyonaka (Ser197Cys) and a Homozygous Apolipoprotein E2/2
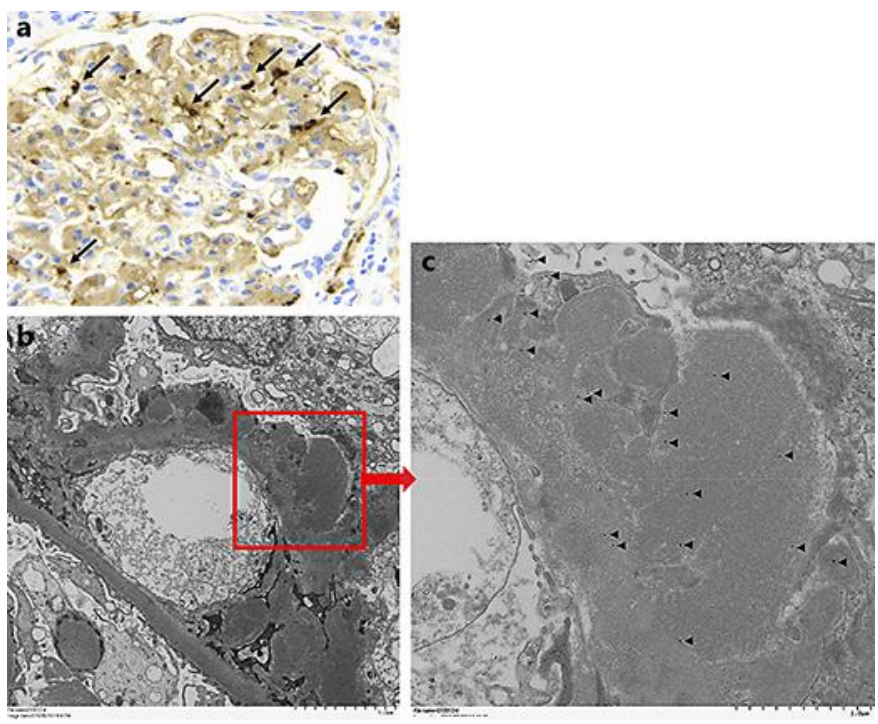

Fig. 3. Immunohistochemical staining for ApoE in the glomerulus. a Light microscopy specimen shows ApoE-positive deposits particularly in the subepithelial areas (arrows). b, c Electron microscopy shows black dots on higher magnification (c, arrowheads), which are positive signals for ApoE. ApoE, apolipoprotein E.

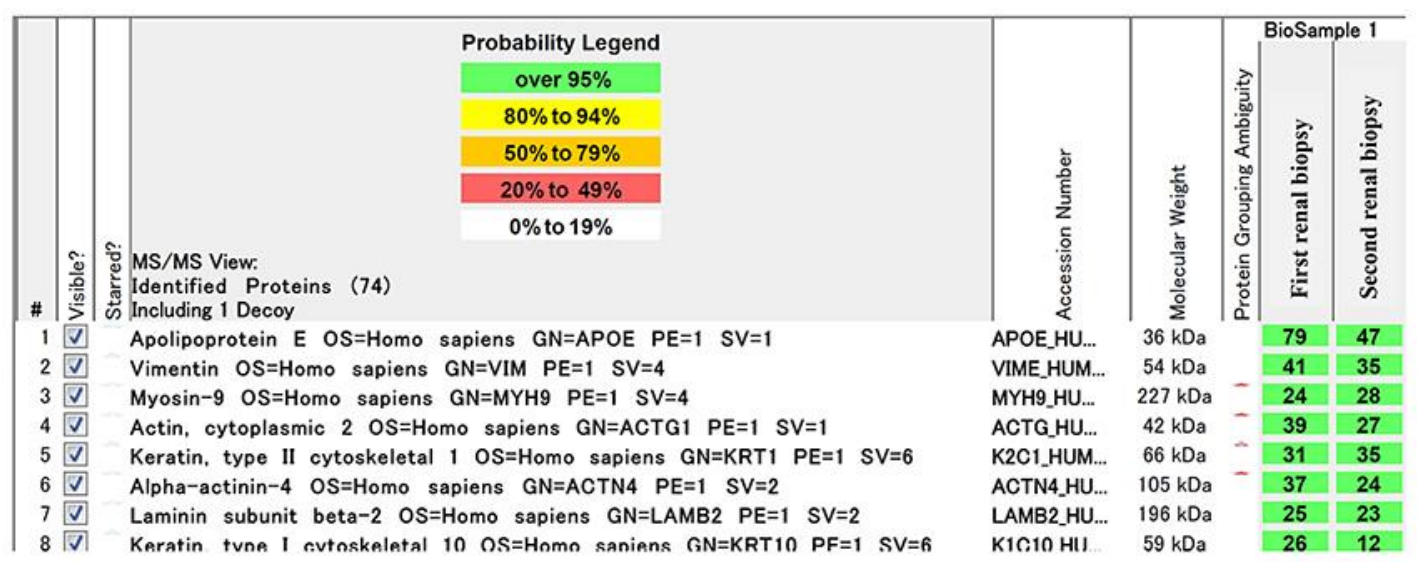

Fig. 4. Summary of amino acid sequence coverage detected in the microdissected samples from the first and the second renal biopsy specimens, which showed high numbers of spectra matching ApoE protein with a probability greater than $95 \%$. ApoE, apolipoprotein E. 


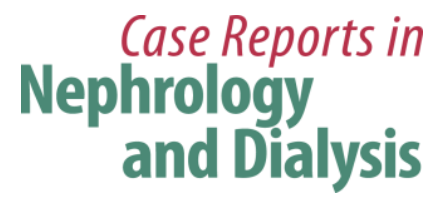

\begin{tabular}{l|l} 
Case Rep Nephrol Dial 2018:8:45-55 \\
\begin{tabular}{l|l} 
DOI: $10.1159 / 000487919$ & $\begin{array}{l}\text { C } 2018 \text { The Author(s). Published by S. Karger AG, Basel } \\
\text { www.karger.com/cnd }\end{array}$
\end{tabular}
\end{tabular}

Fukunaga et al: Membranous Nephropathy-Like Apolipoprotein E Deposition Disease with Apolipoprotein E Toyonaka (Ser197Cys) and a Homozygous Apolipoprotein E2/2

Table 1. Laboratory findings on first admission

\begin{tabular}{|c|c|c|c|}
\hline \multicolumn{2}{|l|}{ Urinalysis } & \multicolumn{2}{|l|}{ Blood chemistry (2) } \\
\hline $\mathrm{pH}$ & 6.5 & AST & $16(10-31) \mathrm{IU} / \mathrm{L}$ \\
\hline Urine-specific gravity & 1.027 & ALT & $15(4-31) \mathrm{IU} / \mathrm{L}$ \\
\hline \multirow[t]{2}{*}{ Protein } & $(3+)$ & LDH & $174(100-211) \mathrm{IU} / \mathrm{L}$ \\
\hline & $2.13 \mathrm{~g} / \mathrm{gCr}$ & ALP & $168(98-328) \mathrm{IU} / \mathrm{L}$ \\
\hline Occult blood & $(3+)$ & $\gamma$-GTP & $12(8-45) \mathrm{IU} / \mathrm{L}$ \\
\hline \multirow[t]{3}{*}{ Casts } & glass & Total cholesterol & $161(130-219) \mathrm{mg} / \mathrm{dL}$ \\
\hline & granular & Triglyceride & $106(32-153) \mathrm{mg} / \mathrm{dL}$ \\
\hline & RBC casts & HDL cholesterol & $50(35-87) \mathrm{mg} / \mathrm{dL}$ \\
\hline $\mathrm{RBC}$ & 50-99/HPF & CRP & $0.64(<0.30) \mathrm{mg} / \mathrm{dL}$ \\
\hline WBC & 5-9/HPF & Glucose & $86(60-110) \mathrm{mg} / \mathrm{dL}$ \\
\hline Urine Bence Jones protein & not detected & HBs antigen & $(-)$ \\
\hline \multicolumn{2}{|l|}{ Casual blood count } & Anti-HCV antibody & $(-)$ \\
\hline WBC & $5,000(3,500-8,500) / \mu \mathrm{L}$ & RPR & $(-)$ \\
\hline $\mathrm{RBC}$ & $402(370-500) \times 10^{4} / \mu \mathrm{L}$ & Serological tests & \\
\hline $\mathrm{Hb}$ & $11.6(11.3-15.0) \mathrm{g} / \mathrm{dL}$ & IgG & $786(870-1,700) \mathrm{mg} / \mathrm{dL}$ \\
\hline $\mathrm{Ht}$ & $35.2(33.0-45.0) \%$ & IgA & $237(110-410) \mathrm{mg} / \mathrm{dL}$ \\
\hline Plt & $25.3(12.0-38.0) \times 10^{4} / \mu \mathrm{L}$ & $\operatorname{IgM}$ & 155 (35-220) mg/dL \\
\hline \multicolumn{2}{|l|}{ Blood chemistry (1) } & Antinuclear antigen & $\times 40(<x 40)$ \\
\hline $\mathrm{Na}$ & 142 (135-147) mEq/L & $\mathrm{CH}_{50}$ & $51.4(23-46) \mathrm{CH}_{50} \mathrm{U} / \mathrm{mL}$ \\
\hline $\mathrm{K}$ & $4.1(3.6-5.0) \mathrm{mEq} / \mathrm{L}$ & Anti-streptolysin 0 & $99(\leq 235) \mathrm{IU} / \mathrm{mL}$ \\
\hline $\mathrm{Cl}$ & $108(98-108) \mathrm{mEq} / \mathrm{L}$ & Anti-streptokinase antibody & $\times 160(\leq \times 1,280)$ \\
\hline Total protein & $5.6(6.7-8.3) \mathrm{g} / \mathrm{dL}$ & Anti-ds-DNA antibody & $\leq 5.0(\leq 10.0) \mathrm{IU} / \mathrm{mL}$ \\
\hline Albumin & $2.7(3.8-5.1) \mathrm{g} / \mathrm{dL}$ & Anti-Sm antibody & $(-)$ \\
\hline BUN & $13(8-20) \mathrm{mg} / \mathrm{dL}$ & Anti-RNP antibody & $(-)$ \\
\hline Creatinine & $0.6(0.30-0.90) \mathrm{mg} / \mathrm{dL}$ & Cryoglobulin & $(-)$ \\
\hline Uric acid & $4.7(2.6-6.0) \mathrm{mg} / \mathrm{dL}$ & Serum immunoelectrophoresis & normal pattern \\
\hline Estimated GFR & $106 \mathrm{~mL} / \mathrm{min} / 1.73 \mathrm{~m}^{2}$ & & \\
\hline
\end{tabular}

Reference values are given in parentheses. RBC, red blood cell; WBC, white blood cell; HPF, high power field; Hb, hemoglobin; Ht, hematocrit; Plt, platelets; BUN, blood urea nitrogen; GFR, glomerular filtration rate; AST, aspartate aminotransferase; ALT, alanine aminotransferase; LDH, lactate dehydrogenase; ALP, alkaline phosphatase; $\gamma$-GTP; $\gamma$-glutamyltransferase; HDL, high-density lipoprotein; CRP, C-reactive protein; $\mathrm{HCV}$, hepatitis $\mathrm{C}$ virus; $\mathrm{RPR}$, rapid plasma reagin. 